\title{
Posiciones sobre aborto en Argentina: de la Conferencia Episcopal a las opiniones de los/as ciudadanos/as católicos/as
}

\author{
Hugo H. Rabbia' \\ María Candelaria Sgró Ruata
}

\section{Resumen}

El aborto continúa siendo un tema de gran controversia en las políticas sexuales de América Latina en general y de Argentina en particular. El artículo analiza la posición oficial de la jerarquía de la Iglesia Católica argentina difundida y defendida a través de los pronunciamientos públicos de la Conferencia Episcopal Argentina (CEA) y las actitudes de ciudadanos/as cordobeses en relación al aborto. Se han combinado técnicas de recolección y análisis de datos cualitativos y cuantitativos con el objeto de aproximarnos a una visión desde las jerarquías y las bases de un sector religioso mayoritario. De esta manera, el trabajo se estructura a partir de dimensiones sobre el aborto inducido, las situaciones de aborto no punible y la percepción de consecuencias de legalización del aborto, entre otras, las que permiten realizar una lectura cruzada de los datos analizados para posteriormente abrir líneas de reflexión en torno a los consensos y resistencias sobre las dimensiones seleccionadas.

Palabras claves: aborto; Iglesia Católica; actitudes hacia el aborto; Argentina.

\section{Presentación}

En América latina diversas cuestiones sobre sexualidad han sido en las últimas décadas objeto de crecientes discusiones públicas. En Argentina en

I Doutorando em Estudios Sociales de América Latina pela Universidad Nacional de Córdoba - UNC, Córdoba, Argentina e Profesor Adjunto na Universidad Católica de Córdoba (UCC), Córdoba, Argentina. É autor de artigos publicados nas revistas América Latina Hoy (2013), Revista Polis (2013), Revista Perfiles Latinoamericanos (20/2), entre outras. E-mail: hrabbia@gmail.com.

2 Doutoranda em Estudios Sociales de América Latina pela Universidad Nacional de Córdoba - UNC, Córdoba, Argentina. É autora de artigos publicados nas revistas Espacio Abierto Cuaderno Venezolano de Sociología (2013), Outras cartografías matrimoniales, Cultura e Sociedade (2012), Revista de Antropología y Sociología (2012),entre outras. E-mail: candelariasgro@yahoo.com. 
particular, desde fines de los ańos noventas, el reconocimiento de derechos sexuales y reproductivos ingresa con mayor intensidad en las agendas legislativas; en consonancia se han sancionado diversas leyes tales como la de Salud Sexual y Procreación Responsable (2002), Educación Sexual Integral (2006), Matrimonio Igualitario (2010), Identidad de Género (2012), entre otras. El aborto, aún cuando se han logrado avances en su legalización-despenalización, continúa siendo uno de los asuntos que presenta mayores resistencias. Estas resistencias se evidencian tanto al momento de su efectivización -a través de la articulación de políticas públicas- como en la producción de un debate que permita discutir la normativa vigente, es decir, para que los proyectos de ley alcancen estado parlamentario y sean discutidos en el ámbito del congreso nacional.

Los avances en el plano legal y los debates en el plano social, fueron y son resistidos por ciertos sectores entre los cuales la jerarquía institucional de la Iglesia Católica adquiere un singular protagonismo. En esta dirección, la reciente elección del cardenal Bergoglio como Sumo Pontífice ha provocado un clima de incertidumbre sobre el tratamiento de los proyectos de interrupción voluntaria del embarazo (IVE) que en la actualidad se encuentran en discusión en las comisiones legislativas del Congreso de la Nación. Vale considerar que Bergoglio, arzobispo de Buenos Aires desde 1998, fue nombrado presidente de la Conferencia Episcopal Argentina en el 2005 (hasta el 2011), periodo en los que se dieron numerosos debates públicos sobre derechos sexuales y reproductivos, frente a los que la Iglesia Católica argentina siempre manifestó su oposición. Entre estos debates, la ley de "matrimonio igualitario" adquiere relevancia por el protagonismo que tuvo el cardenal al ser ampliamente difundida en el espacio de los medios de comunicación, una carta en el que calificaba al proyecto de ley como "la pretensión destructiva al plan de Dios" (LA NACIÓN, 8 de julio de 2010).

Considerando este contexto, el presente trabajo se propone analizar la posición oficial de la jerarquía de la Iglesia Católica argentina difundida y defendida a través de los pronunciamientos públicos de la Conferencia Episcopal Argentina (en adelante, CEA) y las actitudes y religiosidad de ciudadanos/as cordobeses en relación al aborto. Para nuestro objetivo combinamos técnicas de recolección y análisis de datos cualitativos y cuantitativos que nos permiten contrastar las posiciones de la ciudadanía respecto al aborto inducido y las sostenidas por la jerarquía de la Iglesia Católica en documentos difundidos en el espacio público argentino. De esta manera el trabajo se estructura a partir de un conjunto de dimensiones que nos permiten realizar una lectura cruzada 
de los datos analizados para posteriormente abrir líneas de reflexión en torno a las dimensiones seleccionadas.

\section{Aborto en Argentina}

En la mayoría de los países de América Latina, la legislación sobre aborto ${ }^{3}$ es restrictiva, y Argentina no es la excepción a la regla. El aborto es considerado un delito y se encuentra regulado por el Código Penal. Aún cuando existen excepciones a su punibilidad, esto no supone su legalidad, sino que no se penaliza a la mujer en determinadas circunstancias. No obstante, prevé una serie de situaciones de no punibilidad cuando "el aborto (es) practicado por un médico diplomado con el consentimiento de la mujer encinta (...), no es punible: 1) Si se ha hecho con el fin de evitar un peligro para la vida o la salud de la madre y si este peligro no puede ser evitado por otros medios. 2) Si el embarazo proviene de una violación o de un atentado al pudor cometido sobre una mujer idiota o demente. En este caso, el consentimiento de su representante legal deberá ser requerido para el aborto" (Código Penal Argentino, art. 86). El articulado referido a los denominados "abortos no punibles" (en adelante, ANP) ha sido fruto de numerosas interpretaciones habilitando acciones restrictivas de sectores conservadores con base religiosa con el objetivo de cercenar el amparo legal de las mujeres (MAFFIA, 2006).

En esta dirección es relevante mencionar que en el año 2011, el Comité de Derechos Humanos de Naciones Unidas condenó al Estado argentino por su responsabilidad en no garantizar los derechos de LMR, siglas con las que se identificó a una joven discapacitada violada por un familiar a quien se le denegó la interrupción del embarazo en los hospitales públicos contemplada por ley. Así, instó al Estado nacional a realizar las acciones necesarias para garantizar el acceso efectivo en los casos de ANP.

Asimismo, es importante resaltar que en el año 2012, el alcance de la no punibilidad del aborto en situaciones de embarazos producto de una violación fue ratificado por un fallo de la Corte Suprema de Justicia (en adelante, CSJ). De esta manera, dio un paso adelante en la ratificación de un marco interpretativo acorde con lo ya dispuesto por la ley argentina en reconocimiento de los derechos de las mujeres. Además, la CSJ instó al Estado nacional y Estados provinciales para que se avance en la sanción de protocolos

3 En este trabajo la utilización de la nominación "aborto" refiere específicamente a aborto inducido y por lo tanto se diferencia de aborto natural o indirecto (FAÚNDES y BARZELATTO, 2011). 
con el fin de asegurar el acceso efectivo a la interrupción de embarazos en los casos permitidos por la ley.

No obstante, las presiones de los sectores conservadores han dificultado su protocolización y aplicación en diversas provincias ${ }^{4}$. En la provincia de Córdoba, por ejemplo, el protocolo de actuación frente a instancias de ANP por causales de violación se encuentra paralizado por un fallo adverso emitido por el Juzgado Civil y Comercial de $30^{\circ}$ Nominación a cargo del Juez F. Ossola (en el mes de abril del 2012) ${ }^{5}$ dando lugar a los recursos presentados por la asociación civil Portal de Belén.

Si bien no existen estadísticas oficiales, se estima que en Argentina se realizan entre 460 y 600 mil abortos ilegales cada ańo, mientras que alrededor de 80 mil mujeres son hospitalizadas por complicaciones relacionadas a estas prácticas y al menos un centenar de ellas mueren producto de abortos inseguros, en particular, mujeres pobres (PANTELIDES y MARIO, en BASCARY, 2012, p. 379). En este sentido, la problemática del aborto atraviesa diversas cuestiones que repercuten no sólo en las desigualdades de género y en la opresión histórica de las mujeres, sino también en las demás formas de desigualdad existentes y operantes (VAGGIONE, 2012).

Las discusiones públicas sobre aborto en Argentina pueden rastrearse desde la segunda década del siglo XX (HTUN, 2003), no obstante, es a partir de mediados de los ańos 90 que la cuestión adquiere una mayor visibilidad en el espacio público (BROWN, 2008; PECHENY, 2011).

La intención de los sectores conservadores de base religiosa por incluir una cláusula antiabortista en la reforma de la Constitución Nacional de 1994, marca un hito de movilización y articulación en torno a las agendas a favor y en contra de la legalización del aborto. La gestión del ex presidente Carlos Saúl Menem había cimentado una alianza con el conservadurismo religioso que llevaría, entre otras expresiones, a la aprobación de un "Día del Niño por Nacer". La emergencia de organizaciones sociales - muchas de ellas autodenominadas "pro vida"- ha reflejado una politización reactiva de los

4 En la actualidad, sólo cinco de las veinticuatro provincias argentinas se encuentran alineadas con lo dispuesto por la CSJ (INFOJUS, 8 de mayo de 2013).

5 Al momento de cierre de este artículo (mayo de 2013) en la provincia de Córdoba se dio a conocer la sentencia de la Cámara de Apelaciones en lo Civil y Comercial que establece la inaplicabiblidad de la guía de atención de ANP por considerarla inconstitucional (CHAHER, 2013). 
sectores conservadores de base religiosa (VAGGIONE, 2005), los cuales han intentado a través de movilizaciones, amparos judiciales y lobby legislativo frenar cualquier iniciativa de derechos sexuales y reproductivos.

En 2005, el lanzamiento de la "Campaña Nacional por el Derecho al Aborto libre, seguro y gratuito" configura una marca relevante para comprender los modos en que se busca enmarcar la discusión pública sobre aborto desde los sectores pro-derechos. A su vez, traduce la demanda de legalización del aborto en un lenguaje de derechos sexuales más amplio, conexo a las demandas de educación sexual y anticoncepción.

Sin embargo, estos sectores encuentran en la Iglesia Católica uno de los principales obstáculos (VAGGIONE, 2005) que han tenido que enfrentar todas las demandas de derechos sexuales en la región. Es el "actor que lidera intelectualmente y organizativamente la resistencia a cualquier cambio" (PECHENY y DE LA DEHESA, 2009, p. 38). La intervención política de la Iglesia Católica se ha transformado en las últimas décadas: de un accionar directo, donde dirimía la obediencia (o no) de las normas ha pasado a asumir un rol de "tutelaje moral" que supone la publicitación de "sentimientos cívicamente aceptables" en torno a diversas cuestiones sociales, en particular en el terreno de la salud sexual y reproductiva (NUGENT, 2010, p. 34).

La Iglesia Católica no aprueba el aborto bajo ninguna circunstancia, salvo en los casos de aborto indirecto (FIGARI, 2007). Su posición histórica sobre la cuestión ha ido modificándose, pero en la actualidad está contenida principalmente en la Encíclica Evangelium Vitae publicada en 1995 por Juan Pablo II, donde se sostiene que "el aborto procurado es la eliminación deliberada y directa, como quiera que se realice, de un ser humano en la fase inicial de su existencia" y siempre se presenta como "un desorden moral grave". En este sentido, la Iglesia Católica en Argentina y los sectores afines mantienen una posición en términos absolutos respecto al aborto que implica la no intervención, incluso cuando la vida de la mujer corre grave peligro.

La Iglesia Católica en Argentina ha tenido un rol de legitimación social y política a lo largo de gran parte del siglo XX, al punto de asumir un carácter de "nacionalismo de sustitución" para millones de argentinos (MALLIMACI, 2008). A pesar de haber evidenciado un descenso significativo en los últimos años, continúa siendo una institución depositaria de los mayores índices de confianza en términos comparados (LATINOBARÓMETRO, 2011). 
En 2008, la primera encuesta nacional de creencias y actitudes religiosas reveló que el $76,5 \%$ de las/os argentinas/os se identifica como católicas/ os, mientras casi un 9\% manifestó ser evangélica/o y un 11,3\% se declaró indiferente o sin pertenencia religiosa (MALLIMACI, 2010; CUCHETTI, 2010). El análisis de los datos de la encuesta ha permitido advertir que, de las personas identificadas como católicas, solo un 5\% evidencian mayores niveles de adhesión al dogma en temas como el aborto, la sexualidad premarital y el sacerdocio femenino (GIMÉNEZ BELIVEAU e IRRAZÁBAL, 2010). Estos datos coinciden con la mayoría de los estudios sobre actitudes hacia el aborto en diversas sociedades latinoamericanas: las personas tienden a sostener posiciones respecto al aborto y otros temas de moral sexual que no responden rígidamente a los lineamientos trazados por la Iglesia Católica e incluso son más favorables que las legislaciones vigentes en sus respectivos países (DIDES, et al., 2011; CAMPOS, PENNA y MITOFSKY, 2010; PETRACCI, 2011; YAM, DIEZ-DRAFFNER y GARCÍA, 2006; LISTA, 1996)

Ahora bien, ¿`cómo inscribe la Iglesia Católica el aborto en el espacio de lo público en Argentina? ¿A quién/es interpela? Y, ¿está inscripción se refleja en las posiciones de la opinión pública de los ciudadanos/as, en particular, católicos/as? Éstos constituyen algunos de los principales interrogantes que articulan esta presentación.

\section{Notas metodológicas}

El presente trabajo se basa en un análisis de diseño mixto (TEDDLIE y TASHAKKORI, 2003) en el que combinamos datos y análisis cualitativos y cuantitativos de forma secuencial. Las propuestas de metodología mixta apuntan no sólo a la integración metodológica, muchas veces a partir de la combinación de técnicas cualitativas y cuantitativas, sino también a un mayor nivel de comprensión, más comprehensiva y más intuitiva. En relación al abordaje cualitativo, consideramos un corpus analítico compuesto por pronunciamientos públicos de la Conferencia Episcopal Argentina (CEA). El material documental comprende declaraciones y documentos publicados por la CEA en el periodo 2000-2010. En esta primera recopilación, realizamos un análisis temático a partir del cual seleccionamos aquellos documentos que tuvieran al aborto como tema central o como tema secundario. Para el análisis del material utilizamos como herramienta de apoyo, el programa informático 
para análisis de datos cualitativos Atlas.ti que nos permitió trabajar a partir de la codificación del material. Este trabajo fue realizado en primer lugar, con el objetivo de identificar las definiciones de aborto, y en segundo lugar, con el de identificar las categorías emergentes en torno a nuestro tópico de indagación.

En la fase cuantitativa recurrimos a los datos recabados a través de un cuestionario semi-estructurado aplicado de forma domiciliaria a una muestra de 450 ciudadanas/os de la ciudad de Córdoba (Argentina) de 18 a 66 años de edad. Para el diseńo del muestreo se utilizó la metodología de Probabilidad Proporcional al Tamańo (PPT) ${ }^{6}$.

La muestra quedó conformada por un $51.9 \%$ de mujeres y un $48.1 \%$, de varones, proporción semejante a la relevada por el Censo Nacional del INDEC para la ciudad de Córdoba. La media de edad fue de 36,87. Respecto al nivel educativo, el 9,2\% presentó nivel educativo hasta primario completo, $34.9 \%$ de las personas encuestadas presentaron nivel educativo secundario incompleto y secundario completo, mientras que el 55.9\% refirió tener un nivel educativo terciario o universitario incompleto o superior. En cuanto al Nivel Socio-Económico (NSE), el 36\% de las personas encuestadas fue categorizada como de NSE bajo (D1, D2 y E en la categorización de Comisión de Enlace Institucional -AAM, SIEMPRO y CEIM de 2006), un 48\% fueron identificados como de NSE medio bajo y medio típico y un 15,2\%, como de NSE medio alto y alto.

El cuestionario indagó específicamente posicionamientos genéricos en relación a considerar el eje prohibición- legalización del aborto, a la vez que se preguntó si la persona acordaba o no con permitir el aborto en doce situaciones específicas, tales como "cuando el embarazo es fruto de una violación" o "cuando la pareja no desea tener más hijos". También se indagó el conocimiento respecto a instancias de ANP reconocidas por la legislación vigente, así como aspectos referidos a la percepción de punibilidad y penalización de situaciones de aborto ilegal. Finalmente, se indagaron aspectos referidos a la religiosidad personal, tales como la religión de crianza y la religión de pertenencia actual,

6 El método consiste en elegir de manera aleatoria unidades primarias de observación (en este caso, radios censales), dentro de las cuales se seleccionaron manzanas para, por último, elegir viviendas o domicilios al interior de cada manzana. De este último proceso de selección se obtuvieron los casos individuales que fueron encuestados. Esta técnica proporciona una muestra probabilística (con características de aleatoriedad y representatividad). El nivel de confianza se fijó en 97\%, siendo el error muestral de \pm 0.05 
la auto-percepción de religiosidad, la frecuencia de asistencia al culto y el grado de implicación con la comunidad religiosa, entre otros aspectos. Los datos cuantitativos fueron analizados primero de forma univariada, y posteriormente de forma bivariada, a partir de las opciones brindadas por el programa de análisis estadístico SPSS .19.

\section{El aborto en los pronunciamientos públicos de la Conferencia Episcopal Argentina}

La jerarquía de la Iglesia católica desde el Vaticano considera al aborto a partir de la noción de vida, la que es definida desde "la concepción hasta la muerte natural” (MUJICA, 2007; VAGGIONE, 2009). La definición de vida a partir del trazado de su inicio y fin constituye "la persona humana". En líneas generales, en cuanto existe persona humana desde la concepción, cualquier práctica que pudiera ser reconocida como abortiva es vinculada con la muerte. En este sentido y focalizando la mirada en los pronunciamientos de la CEA, resulta interesante mencionar que uno de los documentos que adquiere una referencia reiterativa es la Encíclica Evangelium Vitae, como ya lo señaláramos antes. Este documento inscribe la posición de la jerarquía vaticana y brinda el marco interpretativo (y programático) al cual se alinean los pronunciamientos de la CEA. En la Encíclica se sostiene la gravedad moral del aborto puesto que es colocado en equivalencia al homicidio:

...el aborto procurado es la eliminación deliberada y directa, como quiera que se realice, de un ser humano en la fase inicial de su existencia, que va de la concepción al nacimiento. La gravedad moral del aborto procurado se manifiesta en toda su verdad si se reconoce que se trata de un homicidio $y$, en particular, si se consideran las circunstancias específicas que lo cualifican? ${ }^{7}$.

Otro de los puntos que adquiere insistencia en los pronunciamientos de la CEA y es el que nos interesa subrayar en esta presentación, es la construcción de evaluaciones sobre los marcos legales, es decir, la presencia constante de interpelación y búsqueda de incidencia en la sanción de las leyes. De la correspondencia directa aborto-muerte, se desprenden una serie de relaciones que se inscriben en un campo de disputas políticas. En esta dirección, la muerte

7 Desde aqui en adelante los resaltados son nuestros a excepción de que se explicite lo contrario. 
es asociada al "homicidio" como figura penalizada por la ley y es en esta conexión el núcleo base para el ingreso al debate sobre los marcos legales vigentes.

En esta presentación sostenemos que cuando la CEA considera el aborto se desplaza al campo de las leyes vigentes del Estado para intervenir en los asuntos públicos como agente político, operando en una disyunción estratégica: por un lado, la insistencia en tratar de definir las leyes y por otro, el sustento de la propia posición desconociendo los marcos legales vigentes. En otras palabras, si por un lado, disputa la inscripción de definiciones en la ley (el aborto como un "crimen" en cualquier circunstancia) dando de esta forma legitimidad a los marcos legales, por otro, actúa desconociendo a la ley (por ejemplo, no reconociendo los casos de ANP).

Sobre este desfasaje se articulan los desplazamientos a partir de los cuales la CEA inscribe su posicionamiento público y la búsqueda de intervención política cuando el aborto ingresa en la escena pública a través de demandas de ampliación de derechos o incluso en casos donde se solicitan abortos contemplados como no punibles por el Código Penal argentino.

\section{I Aborto como crimen: sujetos desplazados}

El aborto es construido por la CEA principalmente como un crimen y en tanto tal, las leyes seculares no pueden permitirlo bajo ninguna circunstancia. La relación aborto-crimen es una de las más intensas, es a partir de ella que la CEA busca posicionar el asunto en el espacio de lo público e influir en el "deber ser" de los marcos legales:

Es necesario un marco legal que respete el derecho fundamental a la vida desde la concepción y excluya en absoluto el crimen del aborto. (CEA, 2000a)

... que el homicidio es un crimen tremendo en cualquiera de sus formas, particularmente en el aborto, pues en esa instancia, la vida se encuentra en el grado más alto de vulnerabilidad y de mayor indefensión. (CEA, 2004)

En esta dirección, quiénes son sujetos de derecho se vuelve un punto clave. Si el aborto debe ser prohibido - puesto que es un crimen- en cualquiera de sus circunstancias esta posición es justificada por medio de la idea de "persona no nacida". 
(...) no hay ninguna diferencia entre destrozar el cráneo de esa pequeña criatura ya gestada o cometer el homicidio de un niño que camina por la calle. (CEA, 2006)

Porque una multitud de personas débiles e indefensas, como son los no nacidos, están siendo atropellados en su derecho fundamental a la vida. (CEA, 2000b)

De esta manera, la CEA busca inscribir su discurso en el campo de los derechos humanos conectando la noción de "derecho a la vida" con la de "persona no nacida". Esto es, para la CEA el aborto implica la violación del derecho humano a la vida y como desde el momento de la concepción existe persona humana, la persona concebida es sujeto de derechos.

Ahora bien, la vinculación "persona no nacida" con derechos humanos construye un panorama de relaciones en los que se producen un conjunto de desplazamientos que permiten reconocer características específicas del discurso político de la jerarquía católica. Las mujeres en general y las mujeres embarazadas en particular, constituyen uno de los desplazamientos centrales. Mediante la noción de persona no nacida, se construye al feto como sujeto independiente de la mujer, y como tal, como sujeto de derechos, independiente también de la mujer. La disyunción estratégica opera en la inscripción de la noción de sujeto autónomo: la persona no nacida es sujeto autónomo del cuerpo de la mujer lo que en el mismo movimiento inscribe a la mujer como un sujeto sin autonomía. En este panorama, las mujeres no aparecen como sujetos activos e incluso se encuentran desplazadas como sujeto de derechos.

Si hay código genético distinto, hay una vida humana distinta que tiene la misma dignidad que la de sus progenitores. La creatura humana que se desarrolla en el seno de la madre no es una parte de su cuerpo, de la cual pueda disponer a voluntad. Cortar ese proceso natural por medio del aborto equivale a destruir una vida cuyo desarrollo es autónomo, continuo y progresivo. Por lo tanto su destrucción voluntaria constituye un crimen. (CEA, 2005)

El posicionamiento sostenido por la CEA coloca en el feto (inscripto como persona no nacida) el derecho a la vida como "derecho humano inalienable e irrenunciable" invisibilizando a las mujeres y solidificando un campo de sentidos donde éste es construido como lo que el Estado (las leyes) debe(n) defender.

Así, el mandato reproductivo y la conexión indefectible de las mujeres con la maternidad es el elemento aglutinador de la posición de la jerarquía católica y mediante el cual buscan intervenir en los procesos de debate político: 
Las leyes deben cuidar y defender la vida, el primero de los derechos humanos -inalienable e irrenunciable- y su "santuario" que es la familia. (...) Esto lo reiteramos preocupados por la existencia de proyectos de ley que pretenden legalizar el horrendo crimen del aborto. (CEA, 2003)

\subsection{La "cultura de la muerte": posicionamiento político institucional}

La Encíclica vaticana Evangelium Vitae (1995) utiliza la denominación "cultura de la muerte" para enmarcar todos los posicionamientos que se consideran contrarios a la defensa de la vida humana desde los principios sostenidos por el discurso oficial de la jerarquía católica. Siguiendo estos lineamientos, en la trama que sostiene el posicionamiento de la CEA, el aborto es asesinato de una persona humana y en consecuencia, sólo puede admitirse una legislación prohibitiva que aliente su criminalización en nombre de la "cultura de la vida". En este entrecruzamiento, el derecho al aborto, en cualquier circunstancia, es considerado propulsor de una cultura de la muerte.

Es necesario un marco legal que honre la vida humana; y ayude a afianzar en nuestra Patria la cultura de la vida, evitando manipulaciones que dañan la dignidad de las personas. (CEA, 2000a)

La Iglesia, ante el oscurecimiento del sentido de la ley positiva, ha recordado repetidamente la necesidad de leyes que respeten y promuevan el bien de las personas y de las familias ante los nuevos desafíos que nos interpelan, para que se pueda construir una verdadera cultura de la vida y de la familia. (CEA, 2003)

Así, el par antagónico cultura de la vida vs. cultura de la muerte es uno de los vectores estratégicos de la CEA, a partir del cual estructura su posición y la de los demás actores que intervienen en el campo trazando una línea sólida de división entre un "nosotros/ ellos". Bajo esta línea divisoria se construye la convocatoria a la acción (en nombre del "nosotros") que incluye a los/as ciudadanos/as católicos/as en particular pero se extiende a toda la población (cristianos no católicos y no creyentes) porque se realiza desde las bases del "humanismo". Sin embargo, nos interesa resaltar la especial relevancia adjudicada a los/as legisladores/as.

La interpelación a los legisladores es una constante en los pronunciamientos de la CEA, demarcando el deber ser de las leyes y el Estado al mismo tiempo que la responsabilidad de los decisores políticos como agentes promotores de la "buena" moral. 
En el contexto argentino, la interpelación directa a los decisores políticos toma cuerpo especialmente cuando surgen casos de ANP donde es posible visibilizar el rol de la CEA como agente político buscando impedir la efectiva vigencia de los derechos.

\subsection{Una "cuestión de vida o muerte"}

Si la CEA sostiene la criminalización del aborto en cualquiera de sus circunstancias como un eje transversal en su posicionamiento, al considerar el contexto de producción de los pronunciamientos es posible advertir las acciones de incidencia para impedir la efectivización de los casos de ANP.

Un ejemplo en este sentido es el documento "El aborto es una cuestión de vida o muerte" (23 de agosto de 2006) el que se inscribe en un contexto donde, en dos provincias argentinas, 8 madres de mujeres discapacitadas habían solicitado la interrupción del embarazo producto de una violación, dentro de lo establecido por la ley. En este contexto, la jerarquía de la Iglesia Católica, asume el papel de intervenir desplazando a las mujeres víctimas de violación y al marco legal vigente. Siguiendo a Bourdieu (2000, p. 91) la violencia simbólica "permite a la fuerza ejercerse plenamente al hacerse desconocer en tanto que fuerza y al hacerse reconocer, aprobar, aceptar, por el hecho de presentarse bajo las apariencias de la universalidad - de la razón o de la moral". La carga axiológica del pronunciamiento (el aborto se postula como asesinato) busca ejercer presión sobre la situación, utilizando la violencia simbólica como estrategia. En un contexto de situaciones particularizadas, la CEA coloca la relación aborto/mal (lo moral) como una constante universal, como esencia de las sociedades.

Toda la tradición judeocristiana basada en los mandamientos de la Ley de Dios por miles de años consideró que el aborto es un crimen. ¿Qué luces ha recibido esta nueva cultura, qué revelaciones se nos han manifestado para descubrir que lo que siempre fue un mal tan grande hoy ya no lo es? También en otros tiempos hubo

8 En la provincia de Mendoza, el que finalmente encontró un pronunciamiento a favor de la corte suprema de justicia de Mendoza, luego de un intenso debate en el espacio público en el que intervinieron organizaciones civiles católicas buscando revertir la decisión (Ver, Clarín, 2006, 23 de agosto). Y en la provincia de Buenos Aires, donde las acciones llevadas adelante para impedir o retrasar la autorización realizadas por jueces, médicos y organizaciones civiles derivaron en la no autorización del aborto obligando a la solicitante a acudir al sector privado. Sobre este caso, se puede consultar CLADEM (2011). 
abortos, pero siempre se consideró que era un mal a desterrar. Las culturas cambian, pero los fundamentos esenciales de las personas permanecen. La Ley de Dios y el sentido común nos han enseñado que la vida es un gran bien que debemos preservar desde el momento que comienza. (CEA, 2006)

Este pronunciamiento se produce entonces, para ingresar a la definición de asuntos considerados dentro del marco de las leyes del Estado, más aún, dentro de lo reconocido como derecho. En relación al marco legal, se postula de manera explícita la intención de "impedir la legalización del aborto" marcando en la misma dirección un claro desconocimiento o no-reconocimiento de los marcos legales vigentes. En otras palabras, si en el plano "moral" la CEA busca ejercer violencia simbólica, en el plano legal pareciera ignorar el derecho vigente (o impedir su efectivización). Expresa el documento:

¿Cuál es nuestro móvil al dirigirnos a las autoridades, a nuestros representantes y a todo el pueblo tratando de apostar por la vida e impedir la legalización del aborto?

Estratégicamente, la interpelación se orienta tanto a creyentes como a no creyentes; colocando el debate en "una cuestión de fondo" y apelando al "sentido común" de (todos) los/as ciudadanos/as, delimita el campo de deber moral basado en la construcción del aborto ligado al asesinato de un "un ser ya engendrado que es verdadero sujeto de derechos humanos".

En nuestros días se ha reavivado la polémica sobre la despenalización del aborto con motivo de situaciones muy dolorosas que afectan la vida de una joven discapacitada y de un ser inocente por nacer. Lo trágico de esta situación no puede hacernos olvidar que podemos asesinar a un inocente.

Esta polémica no es una discusión más entre tantas. Es una cuestión de fondo. Nunca, como en este caso, puede decirse que es una cuestión de vida o muerte. Tan es así, que involucra a todos los ciudadanos de cualquier credo o condición social. ¿Cuál será la opción de los argentinos?

Así, si por un lado, se desconocen los marcos normativos vigentes y se apela a la moralidad universal como estrategia de violencia simbólica, por otro, se utiliza el "derecho" (es decir, acude a la figura jurídica del derecho a la vida) del no nacido como objeto y propulsor de la participación. En este entramado, el derecho de las mujeres se desplaza, quedando prácticamente al margen. Las mujeres pasan a ocupar un lugar de "medio" y no un lugar de 
sujetos. Así la operación activa de disyunción estratégica por un lado, reclama el derecho a la vida como universal (humano) pero por otro, lo ubica en un sujeto (definido como persona por nacer) desplazando otro (mujeres, en este caso, víctimas de una violación). El "derecho" es reclamado y desconocido en la misma operación (reclama el derecho a la vida y oculta el derecho al ANP).

Ahora bien, si la criminalización del aborto es lo defendido y sostenido públicamente por la $\mathrm{CEA}$, como única posición posible en relación a los marcos normativos y al "deber" (en tanto responsabilidad) de los decisores políticos, en los/as ciudadanos/as (creyentes y no creyentes) esto adquiere una diversidad de posiciones que abordamos en el apartado siguiente.

Gráfico I. Síntesis de relaciones en torno a la noción de aborto en los pronunciamientos de la CEA (2000-20 I0)

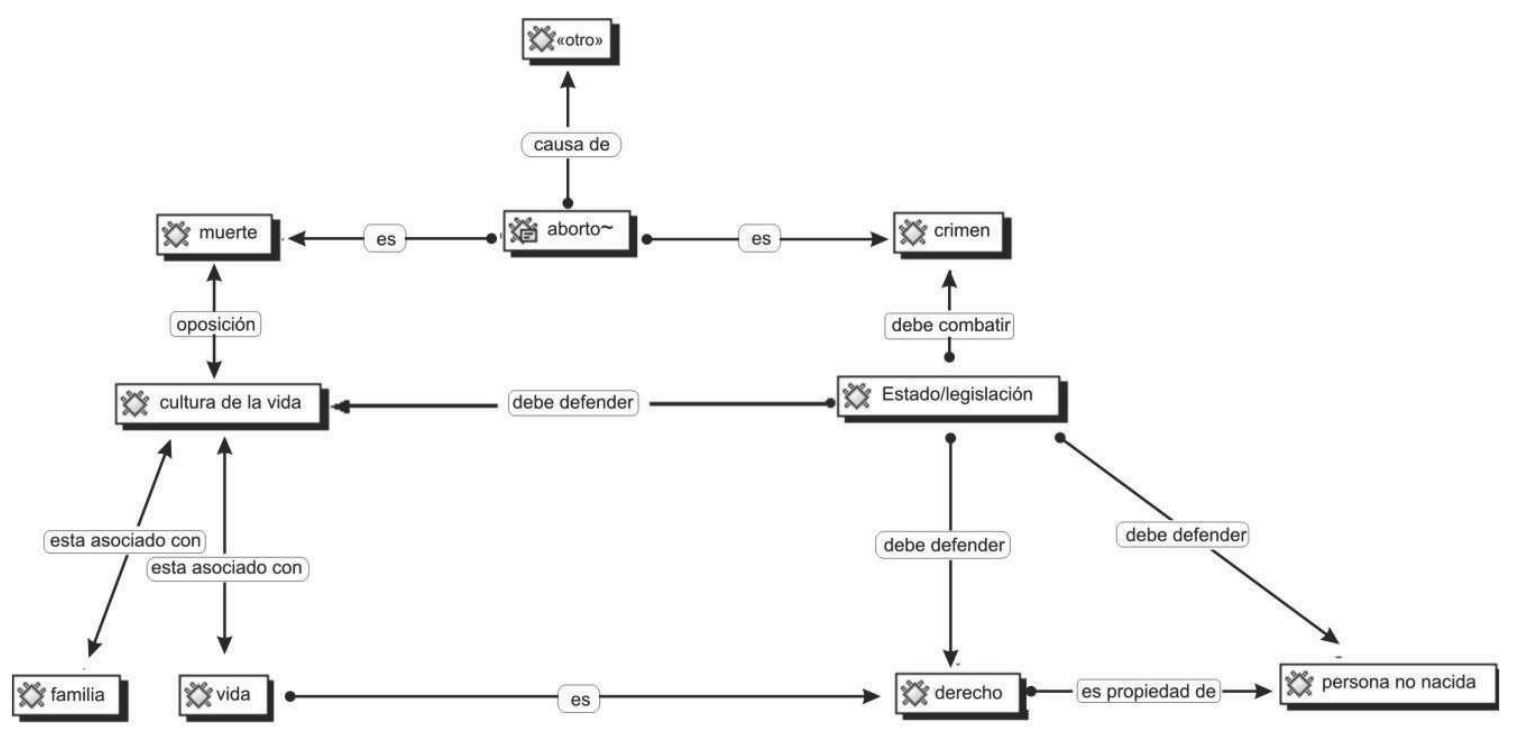

\section{Aborto en la opinión pública de las/os cordobeses}

En primer término, cabe destacar que el posicionamiento genérico de las/ os cordobeses en relación al aborto refleja una tendencia hacia la liberalización a lo largo de los últimos quince ańos: si en 1995, la mitad de la población $(50,8 \%)$ sostenía que el aborto debía estar prohibido en toda circunstancia (LISTA, 1996), en 2011, la posición de rechazo absoluto al aborto en términos genéricos representó un $13,5 \%$ del total de la población, mientras que un $28,5 \%$ consideró que el aborto es un derecho al que las mujeres pueden acceder 
siempre que así lo decidan. La mayoría de las/os cordobeses, en consecuencia, presentó posicionamientos intermedios tendientes a favorables respecto al aborto (media de 3,28 en una escala de 1-5) (Ver Gráfico 2).

Al considerar la religión de pertenencia, se advierte que las personas católicas, que representan un $60 \%$ de la muestra, tienden a reflejar posicionamientos similares a los de la población en general, aunque hay ligeras diferencias con una mayor tendencia a los posicionamientos intermedios y menores proporciones de acuerdo con la idea de que una mujer tiene derecho al aborto siempre que así lo decida. De todas formas, un $84 \%$ de las/ os cordobesas/es exceden la prohibición absoluta del aborto, que constituye la posición oficial de la Iglesia católica. Los/as evangélicos/as, como ya ha sido relevado (JONES, AZPARREN y CUNIAL, 2013), tienden a reflejar proporciones más altas en el posicionamiento de prohibición total, mientras que las personas sin religión reflejan una mayoría de posiciones favorables a considerar el aborto principalmente como un derecho de las mujeres.

Gráfico 2. Posicionamiento en relación al aborto inducido. Proporciones de la población en general y según pertenencia religiosa

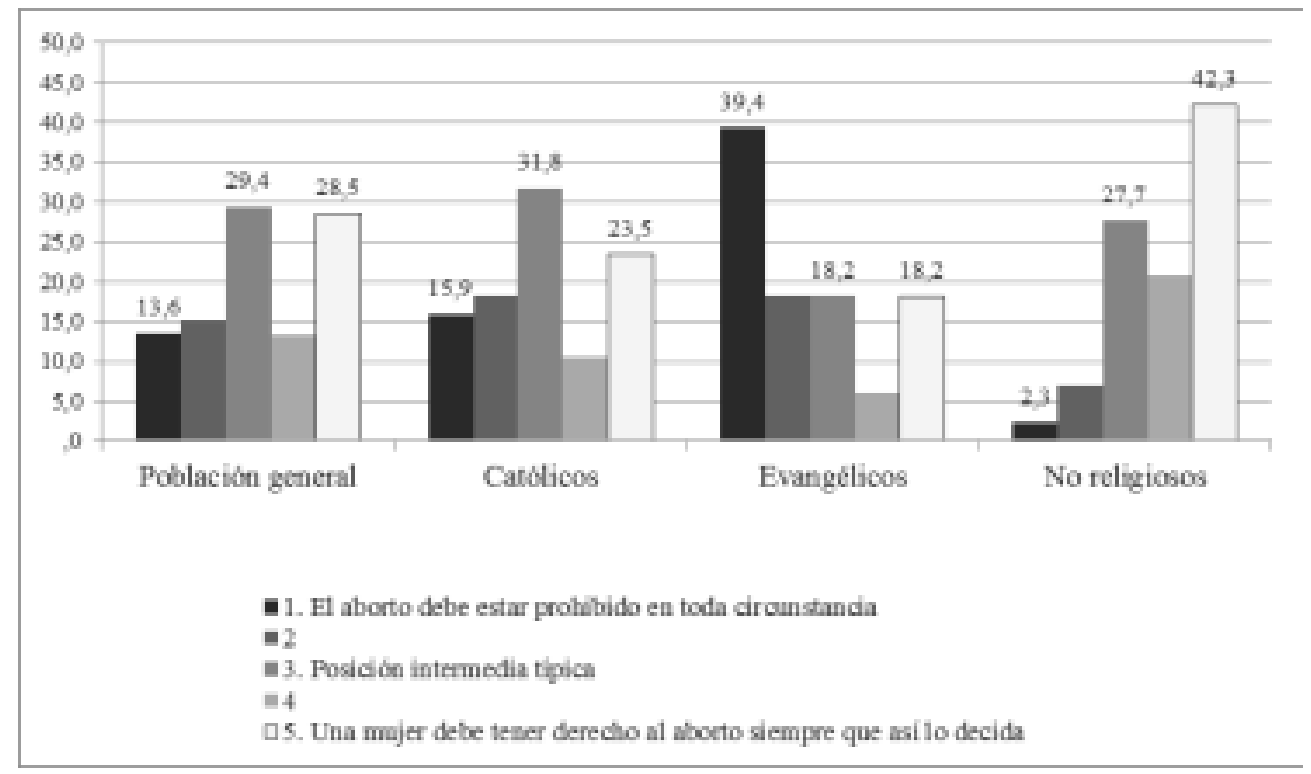

Fuente: elaboración propia (20I I) n=442 (se excluyen casos con valores ausentes)

Entre los/as católicos/as existen posiciones diferentes respecto a quienes se identifican como tales a un nivel más cultural respecto de quienes se pueden 
considerar como practicantes, es decir, que concurren al menos una vez al mes a los servicios religiosos. Las diferencias principales se advierten al nivel de las situaciones específicas en que consideran que el aborto debería estar permitido.

Si los/as católicos/as en general aprueban mayoritariamente la legalización del aborto para todas aquellas situaciones denominadas traumáticas, los/as católicos/ as practicantes (que reflejan un 38\% de la población en general) presentan acuerdos mayoritarios sólo en tres situaciones: cuando el embarazo es producto de una violación, cuando corre peligro la vida de la mujer y cuando la embarazada es débil mental. Estas tres situaciones coinciden con una interpretación textual de la aplicación del articulado de ANP. En este sentido, las personas católicas practicantes de la ciudad de Córdoba sostienen un posicionamiento respecto al aborto que puede definirse como legalista o contenido por la legislación vigente a nivel nacional en relación al aborto. En definitiva, una posición que también puede interpretarse desde lo que en este trabajo denominamos contradicción disyunción estratégica: se asienta en las normativas vigentes pero sin excederla, sin presuntamente habilitar a nivel de opinión pública la discusión sobre modificaciones de esta legislación que habiliten permitan la realización del aborto en otras o todas las situaciones (Ver Tabla 1).

Tabla I. Proporciones de acuerdo con la legalización del aborto en situaciones específicas

\begin{tabular}{|c|c|c|c|c|c|}
\hline & \multirow[t]{2}{*}{ Debe estar permitido el aborto si... } & \multicolumn{2}{|c|}{$\begin{array}{l}\text { Católicos en } \\
\text { general }\end{array}$} & \multicolumn{2}{|c|}{$\begin{array}{c}\text { Católicos } \\
\text { practicantes }\end{array}$} \\
\hline & & Sí (\%) & No $(\%)$ & Sí (\%) & No $(\%)$ \\
\hline \multirow{5}{*}{$\begin{array}{l}\text { Aborto } \\
\text { traumático }\end{array}$} & El embarazo es producto de una violación & 81,2 & 18,8 & 60,5 & 39,5 \\
\hline & El embarazo pone en peligro la vida de la mujer & 77,4 & 22,5 & 66,7 & 33,3 \\
\hline & La mujer embarazada es débil mental & 69,0 & 31,0 & 53,0 & 47,0 \\
\hline & $\begin{array}{l}\text { Hay alguna evidencia médica de que el niño por nacer } \\
\text { pueda sufrir malformaciones }\end{array}$ & 51,6 & 48,4 & 33,7 & 66,3 \\
\hline & La mujer embarazada tiene HIV/Sida & 52,8 & 47,2 & 42,7 & 57,3 \\
\hline \multirow{7}{*}{$\begin{array}{l}\text { Aborto } \\
\text { socio- } \\
\text { electivo }\end{array}$} & La mujer es menor de edad & 37,3 & 62,7 & 26,5 & 73,5 \\
\hline & La pareja no puede sostener económicamente al futuro niño & 35,2 & 64,8 & 24,1 & 75,9 \\
\hline & $\begin{array}{l}\text { El embarazo pone en peligro la salud de la mujer, aunque } \\
\text { no su vida }\end{array}$ & 26,6 & 73,4 & 28,0 & 72,0 \\
\hline & La mujer teme que su futuro hijo pueda ser deforme & 30,8 & 66,7 & 18,3 & 81,7 \\
\hline & La mujer no tiene hijos pero no desea tenerlos & 27,7 & 72,3 & 14,5 & 85,5 \\
\hline & La mujer o la pareja ya tienen hijos y no desean tener más & 22,4 & 77,6 & 14,5 & 85,5 \\
\hline & $\begin{array}{l}\text { La mujer es soltera y fue abandonada por el padre del } \\
\text { futuro niño }\end{array}$ & 17,9 & 82,1 & 9,8 & 90,2 \\
\hline
\end{tabular}

Fuente: elaboración propia (2011) N=445. Nota: en gris, proporciones mayores al 50,1\% 
Ahora bien, casi la mitad de los/as católicos/as tienen una percepción del aborto como delito que sugiere un marcado desconocimiento respecto a la legislación de ANP vigente. La situacionalidad de las actitudes respecto al aborto, es decir, un ponerse en el lugar de la mujer o la familia en situaciones específicas, parece impactar en el conocimiento de situaciones de ANP (por ejemplo, la diferenciación entre reconocer como permitido por la ley argentina un aborto a una mujer víctima de una violación sea esta menor de edad o adulta). Si bien el fallo de la Corte Suprema que clarifica el alcance del articulado sobre ANP aplicable a casos de violación es posterior a la toma de los datos, la diferenciación señalada sugiere una deseabilidad de que la ley permita el aborto cuando la persona es menor de edad y no cuando es adulta. (Ver Tabla 2)

Tabla 2. Proporciones de conocimiento ANP y consecuencias percibidas de la legalización del aborto

\begin{tabular}{|c|c|c|c|c|c|}
\hline & \multirow{3}{*}{$\begin{array}{l}\text { Está permitido por la ley } \\
\text { argentina... }\end{array}$} & \multicolumn{2}{|c|}{ Católicos en general } & \multicolumn{2}{|c|}{ Católicos practicantes } \\
\hline & & \multicolumn{2}{|c|}{$\mathrm{n}=264$} & \multicolumn{2}{|c|}{$\mathrm{n}=180$} \\
\hline & & Sí (\%) & No $(\%)$ & Sí (\%) & No $(\%)$ \\
\hline \multirow{3}{*}{ Situaciones } & $\begin{array}{l}\text { Aborto por mujer adulta víctima } \\
\text { de violación }\end{array}$ & 57,2 & 42,8 & 58,8 & 41,2 \\
\hline & $\begin{array}{l}\text { Aborto de menor edad víctima } \\
\text { de violación }\end{array}$ & 45,3 & 54,7 & 47,5 & 52,5 \\
\hline & $\begin{array}{l}\text { Aborto de una mujer que, de } \\
\text { seguir su embarazo, corra riesgo } \\
\text { su vida }\end{array}$ & 46,6 & 53,4 & 46,8 & 53,2 \\
\hline \multirow{6}{*}{$\begin{array}{l}\text { Consecuencias } \\
\text { percibidas de la } \\
\text { legalización del } \\
\text { aborto }\end{array}$} & Si el aborto es legalizado ... & $\begin{array}{l}\text { Totalmente } \\
\text { de acuerdo } \\
\text { + Bastante } \\
\text { de acuerdo }\end{array}$ & $\begin{array}{c}\text { Poco de } \\
\text { acuerdo + } \\
\text { Nada de } \\
\text { acuerdo }\end{array}$ & $\begin{array}{c}\text { Totalmente } \\
\text { de acuerdo + } \\
\text { Bastante de } \\
\text { acuerdo }\end{array}$ & $\begin{array}{c}\text { Poco de } \\
\text { acuerdo + } \\
\text { Nada de } \\
\text { acuerdo }\end{array}$ \\
\hline & Aumentaría número de abortos & 63,2 & 36,8 & 70,6 & 29,4 \\
\hline & $\begin{array}{l}\text { Las personas se sentirían menos } \\
\text { responsables respecto a su } \\
\text { sexualidad }\end{array}$ & 58,7 & 41,3 & 77,6 & 22,4 \\
\hline & $\begin{array}{l}\text { Habrá menos muertes de } \\
\text { mujeres por abortos inseguros }\end{array}$ & 86,1 & 13,9 & 77,6 & 22,4 \\
\hline & $\begin{array}{l}\text { Las mujeres que aborten sufrirán } \\
\text { menos rechazo social y menos } \\
\text { traumas psicológicos }\end{array}$ & 45,5 & 54,5 & 44,4 & 55,6 \\
\hline & $\begin{array}{l}\text { Se habrá reconocido el derecho } \\
\text { de las mujeres a su propio cuerpo }\end{array}$ & 54 & 46 & 44,7 & 55,3 \\
\hline
\end{tabular}

Fuente: elaboración propia (201I) Nota: en gris, proporciones mayores al 50,1\% 
Es respecto a la percepción de consecuencias de una posible legalización del aborto donde se advierte una diferencia relevante entre católicos/as en general y católicos/as practicantes en particular. Estas afirmaciones se indagaron con el objeto de reconocer el nivel de pregnancia de otros discursos presentes en las disputas públicas en torno al aborto. La mayoría de las/os católicas/os considera que, en caso de aprobarse la legalización del aborto, aumentaría el número de abortos realizados a la vez que habráía menos muertes de mujeres por abortos inseguros. A su vez, se evidencia una diferencia en cuanto a la percepción de las/os católicas/os en general y las/os practicantes, siendo estas/ os últimas/os quienes más consideran que la legalización del aborto conllevará una mayor irresponsabilidad de parte de las personas sobre su sexualidad. Por un lado, es posible considerar estas posiciones en clave de "pánico moral" (Herdt, 2009): la legalización del aborto implicaría no sólo un incremento en su práctica sino también el ejercicio de una sexualidad no responsable, y por lo tanto es vivido como un peligro que es necesario evitar. Por otro, se advierte una pregnancia de uno de los argumentos más frecuentes entre los sectores a favor de la legalización del aborto: que el aborto ilegal ocasiona la muerte evitable de numerosas mujeres. La creencia de que la legalización del aborto no apartará a las mujeres del estigma social que genera su clandestinidad es compartida entre católicos/as, aunque este aspecto se diferencia marcadamente en las personas no religiosas o sin religión de pertenencia, que consideran que consideran en un $65,4 \%$ que la legalización del aborto conducirá a una reducción del trauma psicológico y a la aceptación social de las mujeres que aborten. Por último, cabe destacar la diferencia más significativa en cuanto a las percepciones de las consecuencias de la legalización del aborto: la mayoría de las/os católicas/os en general afirman que se habrá reconocido el derecho de las mujeres a su propio cuerpo (54\%), mientras que entre las/os católicas/os practicantes, el acuerdo en esta afirmación desciende diez puntos, aunque al menos un $44,7 \%$ de este segmento se posiciona en una concepción del aborto como un derecho de la mujer.

Finalmente interesa resaltar que, al indagar quién debe tomar la decisión de practicar un aborto, sólo dos casos de toda la muestra seńalaron que debía ser la Iglesia Católica. Desde sectores conservadores se ha sostenido frecuentemente la necesidad de judicialización (obtener una autorización judicial) en los casos de ANP, aunque la Corte Suprema ha descartado este requisito en numerosas 
ocasiones. No obstante, la población cordobesa considera que quien debe tomar la decisión de practicar un aborto es la mujer y su pareja $(36,4 \%)$ o sólo la mujer (30,6\%). Entre las/os católicos/as en general, sólo un 12\% considera que es la Justicia la que debe tomar la decisión de practicar un aborto, mientras que la mayor proporción corresponde a la mujer y su pareja $(37,2 \%)$. Entre los/as católicos/as practicantes, por su parte, un $20 \%$ se atiene a la posición oficial de la Iglesia católica y considera que nadie debe tomar la decisión de practicar un aborto, mientras que una proporción mayor que en otros segmentos afirma que la decisión debería quedar en manos de los médicos $(17,5 \%)$ o de la Justicia $(15,4 \%)$.

\section{Líneas de cierre}

En esta presentación nos propusimos abordar la posición de la jerarquía católica argentina respecto al aborto y, en la misma dirección, las actitudes y religiosidad de los/as ciudadanos/as cordobeses. Sostenemos que en el posicionamiento público de la CEA opera con una disyunción estratégica. En este trabajo utilizamos esta denominación para remarcar la presencia de operaciones de imprecisión en los posicionamientos respecto al aborto en general y a los casos de ANP en particular. Si la CEA construye al aborto en conexión con la inscripción de otras nociones (como la de persona no nacida, la vida desde la concepción, entre otras) lo hace a partir de una fluctuación entre la necesidad de influir en el establecimiento de la ley y el desconocimiento o no-reconocimiento de los marcos legales vigentes. Asimismo, y en la misma dirección si por un lado utiliza figuras como el "derecho a la vida" en el marco de los derechos humanos, por otro, desplaza los derechos vigentes por ejemplo, en la generación de estrategias de incidencia orientadas a impedir la efectivización del derecho en los casos de ANP. Del mismo modo, si por un lado, busca inscribir la noción de sujetos autónomos (para alentar una visión de sujetos de derecho), por otro, parcializa el quién es sujeto de derecho, desplazando a las mujeres.

Ahora bien, es posible sostener que los/as ciudadanos/as cordobeses se distancian en sus posiciones frente al aborto respecto a lo sostenido y defendido por la jerarquía institucional de la Iglesia Católica, aún entre aquellos que se autoidentifican como creyentes (practicantes o no). De allí que el panorama que presentan los ciudadanos excede la posición categórica de la CEA e 
incluso el de los marcos normativos vigentes. En este sentido, sería interesante considerar, o en su defecto, repensar los vínculos a veces supuestos entre la voz oficial de la ICA y la de sus fieles. Si bien, es posible ver conexiones directas entre el posicionamiento de ambos, éstas no son necesariamente equivalentes. En la ciudadanía, las posiciones adquieren mayor pluralidad en relación al aborto, incluso como dijimos antes, entre quienes se autoidentifican como católicos/as.

En concordancia con resultados relevados por otros estudios (PETRACCI, 2011; DIDES et al., 2010), las actitudes hacia el aborto en general, y las actitudes hacia el aborto en situaciones específicas de las/os ciudadanos/as de Córdoba resultan complejas y ambivalentes. Por un lado, se advierte que las personas, incluyendo las personas católicas (practicantes o no) toman posiciones que exceden la de la jerarquía católica en general: sólo un porcentaje minoritario (no supera el 10\% de la población en general) sostiene una negativa absoluta respecto a la legalización del aborto, mientras que la gran mayoría de la población, en particular los/as católicos/as, tienden a consensuar respecto a que el aborto debería estar permitido en situaciones que consideran traumáticas. La legalización del aborto en causales consideradas más afectivas o por motivos económicos de las mujeres tiende a despertar más rechazos, incluso entre quienes sostienen de forma genérica que el aborto es un derecho al que las mujeres deberían tener acceso.

Si bien la mayoría de la población acuerda con la legalización del aborto en al menos tres situaciones (por embarazo producto de violación, si corre peligro la vida de la mujer y si la mujer es débil mental), las cuales concuerdan con causales contempladas por la legislación de ANP vigente, el nivel de conocimiento sobre esta legislación es relativamente bajo. La mitad de la población considera que estas situaciones no están permitidas por ley, señalando un déficit perceptual en las respuestas legislativas sobre demandas de aborto en la población. La imprecisión que sugieren estos posicionamientos permite pensar en las múltiples concepciones subyacentes a las actitudes hacia el aborto de las personas: moralidad, religiosidad, legalidad se combinan con expresiones desde las propias vivencias cotidianas de las personas para configurar sus posiciones. Al indagar los argumentos que se consideran consecuencias posibles de la legalización del aborto en el país, es posible identificar diversos niveles de pregnancia de estas concepciones: 
se articulan tanto algunos argumentos de los sectores conservadores, entre ellos de la Iglesia Católica, como de los sectores pro-derechos. El derecho de las mujeres al aborto aparece, sin embargo, como una posición deseable para una proporción creciente de personas, pero no se concibe en términos absolutos, como puede observarse respecto a las respuestas en relación a los/as responsables de la decisión de practicar un aborto.

En síntesis, es necesario repensar las vinculaciones, a veces directas, que se realizan cuando se asimilan las opiniones sobre el aborto de la jerarquía eclesiástica con las posiciones de los/as propios/as católicos/as. Al mismo tiempo, al considerar el rol político que ha adquirido la oposición a las demandas de derechos sexuales y reproductivos de la Iglesia Católica en América Latina en general y en Argentina en particular, es necesario problematizar a quién están representando estas posiciones. Ambas cuestiones abren una serie de cuestionamientos que requieren atención si pensamos en la necesidad de rediscutir las relaciones entre política y religión. Las opiniones oficiales de la Iglesia Católica también han sido desafiadas por diversas expresiones de "disidencia religiosa", como ser algunos/as referentes de las teologías feministas u organizaciones que se adscriben como católicas, pero sostienen una agenda pro-derechos (como Católicas por el Derecho a Decidir) (VAGGIONE, 2005). El proceso de reconstruir estas complejidades en los vínculos entre religión institucional y religiosidad personal en torno a las políticas sexuales, en particular, del aborto, constituyen aún un desafío que requiere profundizar las discusiones en nuestro contexto sociopolítico actual.

\section{Referencias}

ALVAREZ, M. Y BREHM, J. American ambivalence towards Abortion Policy: development of a heteroskedastic probit model of competing values. American Journal of Political Science. v. 39, n. 4, 1995. p. 1055-1082.

BASCARY, L. Aborto legal, seguro y gratuito: las consecuencias de la falta de debate. In: CELS, Derechos humanos en Argentina, Informe 2012. Buenos Aires: Siglo XXI, 2012. p. 377-400.

BOURDIEU, P. Cosas Dichas. Buenos Aires: Gedisa, 2000.

BROWN, J. La cuestión del aborto en Argentina. Una mirada a partir de la prensa periódica (1). Question, v. 1, n. 20, 2008. [En línea] <http://perio.unlp.edu.ar/ojs/index.php/question/article/ viewArticle/688>. 
CAMPOS, R.; PENNA, C. Y CONSULTA MITOFSKY, Encuestas de Mitofsky. In: RODRIGUEZ ARAUJO, O. (coord.) La Iglesia contra México. México DF: Orfila, 2010. p. 49-75.

CHAER, S. Es una sentencia de facto, desconoce todo el derecho vigente en las últimas décadas. Comunicar Igualdad, 18 de mayo, 2013. [En línea] <http://www.comunicarigualdad.com.ar/ es-una-sentencia-de-facto-desconoce-todo-el-derecho-vigente-en-las-ultima-decadas/>

CLADEM. Caso LMR c. Argentina. Boletín Cladem, Lima, Año 1, n. 2, 2011.

CLARÍN. La corte mendocina autorizó el aborto a la chica discapacitada. Portal Clarín. 23 de agosto, 2006. [En línea] <http://edant.clarin.com/diario/2006/08/23/sociedad/s-02615.htm>.

CUCHETTI, H. Religiones especulares: ¿confesionalización, secularización o desencantamiento? Sociedad y Religión, v. XX, n. 32/33, 2010, p. 81-98.

DIDES, C.; BENAVENTE, M.C.; SÁEZ, I. Y MORÁN FAÚNDES, J.M. Estudio de opinión pública sobre aborto y derechos sexuales y reproductivos en Brasil, Chile, México y Nicaragua. Santiago de Chile: FLACSO, 2011.

FAÚNDES, A. Y BARZELATTO, J. El drama del aborto: En busca de un consenso. Buenos Aires: Paidós, Tramas Sociales, 2011.

FIGARI, C. Sexualidad, religión y ciencia: discursos científicos y religiosos acerca de la sexualidad, Córdoba: Encuentro Grupo Editor, 2007.

GIMÉNEZ BELIVEAU, V. e IRRAZÁBAL, G. Católicos en Argentina: hacia una interpretación de su diversidad. Sociedad y Religión, v. XX, n. 32/33, 2010, p. 42-59.

HERDT, G. Moral Panics, Sex panics: fear and the fight over sexual rights. New York y London: New York University Press, 2009.

HTUN, M. Sex \& the State: abortion, divorce and the family under Latin American dictatorships and democracies. Cambridge (EEUU): Cambridge University Press, 2003.

INFOJUS. Aborto no punible: el fallo de la Corte. Buenos Aires: Agencia Nacional de Noticias Jurídicas, 8 de mayo, 2013.

JONES, D.; AZPARREN ALMERÍA, A.L y CUNIAL, S. Derechos reproductivos y actores religiosos: los evangélicos frente al debate sobre la despenalización del aborto en la Argentina contemporánea (1994-2011). Espacio Abierto. Cuaderno Venezolano de Sociología, v. 22, n. 1, enero-marzo, 2013, p. $110-133$.

LA NACION. Bergoglio dice que la boda gay "es la pretensión destructiva del plan de Dios”. Portal lanacion.com. 8 de julio, 2010. [En línea] <http://www.lanacion.com. ar/1282778-bergoglio-dice-que-la-boda-gay-es-la-pretension-destructiva-del-plan-de-dios $>$. 
LATINOBARÓMETRO. Informe 2011. [En línea] <http://www.infoamerica.org/primera/ lb_2011.pdf>.

LISTA, C. (1996) ¿Existe consenso hacia el aborto inducido?: Tendencias de la población de la ciudad de Córdoba. Anuario CIJS. v. 3, p. 151-171.

MAFFIA, D. Aborto no punible: ¿Qué dice la ley argentina? In: CHECA, S. (comp.) Realidades y coyunturas del aborto. Entre el derecho y la necesidad. Buenos Aires: Paidós. 2006.

MALLIMACI, F. Entre lo "que es" y lo que "queremos que sea": secularización y laicidad en la Argentina. Sociedad y Religión, v. XX, n. 32/33, 2010 2010, p. 8-30.

MALLIMACI, F. Las paradojas y las múltiples modernidades en Argentina. In: MALLIMACI, F. (comp). Modernidad, religión y memoria, Buenos Aires: Colihue, 2008, p. 75-90

MUJICA, J. Economía política del cuerpo: La reestructuración de los grupos conservadores y el biopoder. Lima: Promsex, 2007.

NUGENT, G. El orden tutelar: Sobre las formas de autoridad en América Latina. Lima: CLACSO, 2010.

PECHENY, M. y DE LA DEHESA, R. Sexualidad y políticas en América Latina: un esbozo para la discusión. Ponencia presentada en Diálogo Latinoamericano sobre Sexualidad y Geopolítica, SPW, Río de Janeiro, 24-26 agosto, 2009. [En línea] <http://www.sxpolitics.org/es/?p=1000>.

PECHENY, M. Yo no soy progre, soy peronista. ¿Por qué es tan difícil discutir políticamente sobre aborto? In: PECHENY, M. y BERGALLO, P. (comps.) Aborto y justicia reproductiva. Buenos Aires: Ed. del Puerto, 2011, p. 91-114.

PETRACCI, M. La opinión pública sobre el aborto en Argentina. In: CÁCERES, C.; M. MOGOLLÓN, E.; PÉREZ-LUNA, G. Y OLIVOS, F. (eds.) Sexualidad, ciudadanía y derechos humanos en América Latina. Lima: IESSDEH, UPCH, 2011, p. 237-246.

TEDDLIE C. y TASHAKKORI, A. A General Typology of Research Designs Featuring Mixed Methods. Research in the Schools. Mid-South Educational Research Association, v. 13, n. 1, 2003, p. $12-28$

VAGGIONE, J. M. Introducción. In: MORÁN FAÚNDES, J. et al. Sexualidades, desigualdades y derechos: Reflexiones en torno a los derechos sexuales y reproductivos. Córdoba, Ciencia, Derecho y Sociedad Editorial, 2012, p. 13-57.

VAGGIONE, J. M. La sexualidad en el mundo post secular. El activismo religioso y los derechos sexuales y reproductivos. In: GERLERO, M. (coord.). Derecho a la Sexualidad. Buenos Aires: Grinberg, 2009. 
VAGGIONE, J.M. Los roles políticos de la religión. Género y Sexualidad más allá del Secularismo. In: VASSALLO, Marta. En nombre de la vida. Córdoba: CDD, 2005, p. 137-167

YAM, E. A.; DIEZ-DRAFFNER, I. YGARCÍA, S. G. Abortion opinion research in Latin America and the Caribbean: A review of the literature. Studies in Family Planning. v. 37, n. 4, 2006, p. 225-240.

\section{Documentos referenciados}

Conferencia Episcopal Argentina (CEA). La buena noticia de la vida humana y el valor de la sexualidad. 11 de agosto, 2000a.

Conferencia Episcopal Argentina (CEA). Reconciliación de los bautizados. Confesión de las culpas, arrepentimiento y pedido de perdón de la Iglesia en la Argentina, realizado en el acto de apertura del Encuentro Eucarístico Nacional. 8 de septiembre, 2000b.

Conferencia Episcopal Argentina (CEA). La familia: imagen del amor de dios. Declaración de la 87 Asamblea Plenaria de Obispos. 15 de mayo, 2004.

Conferencia Episcopal Argentina (CEA). El aborto es cuestión de vida o muerte. 23 de agosto, 2006. Conferencia Episcopal Argentina (CEA). Apostemos siempre por la vida”. Declaración de la 140a Reunión de la Comisión Permanente del Episcopado. 15 de marzo, 2005.

Conferencia Episcopal Argentina (CEA). Familia, Comunión de Amor, tarea de todos. Declaración de la 86a Asamblea Plenaria de Obispos. 15 de noviembre, 2003.

JUAN PABLO II. Encíclica Evangelium Vitae. 1995.

Recebido em: 13/06/2013

Aprovado em: 06/12/2013

\section{Positions on abortion in Argentina: from the Episcopal Conference to the Catholic citizens' opinions}

\section{Abstract}

Abortion is a controversial topic in the sexual politics of Latin America countries and Argentina in particular. The paper analyze the opinion toward abortion from the Catholic Church hierarchy, publicly sustained through official documents by the Argentinean Episcopal Conference (CEA) and the attitudes toward abortion of citizens from Cordoba/Argentina. We combine qualitative 
and quantitative data to explore these opinions by the catholic hierarchies and self-identified catholics. We analyze different dimensions, as the induced abortion, non penalized abortion laws and the perceptions of the consequences that will carry the legalization of abortion in the country, and the likes. These dimensions allow us to reflect about the consensus and resistances on the abortion in Argentina.

Keywords: abortion / Catholic Church / attitudes toward abortion / Argentina 